\title{
Health-related quality of life associated with diabetic retinopathy in patients at a public primary care service in southern Brazil
}

Ângela Jornada Ben'1

Camila Furtado de Souza ${ }^{2}$

https://orcid.org/0000-0003-3439-4995

Franciele Locatelli ${ }^{3}$

https://orcid.org//0000-0002-1448-2034

Ana Paula Oliveira Rosses ${ }^{4}$

https://orcid. org/0000-0003-0717-7661

Adriana Szortika ${ }^{5}$

https://orcid.org/0000-0003-3244-4207

Aline Lutz de Araujo ${ }^{\circ}$

https://orcid. org/0000-0002-6009-1069

Gabriela de Carvalho ${ }^{3}$

https://orcid.org/0000-0001-8124-950X

Daniel Lavinsky 3

https://orcid.org/0000-0001-7197-1259

Jeruza Lavanholi Neyeloff ${ }^{7}$

https://orcid. org/0000-0002-4413-0494

Cristina Rolim Neumann ${ }^{8}$

https://orcid.org/0000-0002-0977-6302

\begin{abstract}
Objective: This study aimed to establish the utility values of different health states associated with diabetic retinopathy in a Brazilian sample to provide input to model-based economic evaluations. Subjects and methods: This cross-sectional study was performed in a sample of patients with type 2 diabetes mellitus (T2D) who underwent teleophthalmology screening at a primary care service from 2014 to 2016. Five diabetic retinopathy health states were defined: absent, non-sight-threatening, sight-threatening, and bilateral blindness. Utility values were estimated using the Brazilian EuroQol five dimensions (EQ-5D) tariffs. Descriptive statistics were calculated. Analysis of covariance was performed to adjust the utility values for potential confounders. Results: The study included 206 patients. The mean ( \pm standard deviation [SD]) utility value was $0.765 \pm 0.19(95 \%$ confidence interval $[\mathrm{Cl}], 0.740-0.790)$. The adjusted mean utility value was $0.748(95 \% \mathrm{Cl}, 0.698-0.798)$ in patients without diabetic retinopathy, 0.752 (95\% Cl, 0.679-0.825) in those with non-sight-threatening state, $0.628(95 \% \mathrm{Cl}, 0.521-0.736)$ in those with sight-threatening state, and $0.355(95 \% \mathrm{Cl}, 0.105-0.606)$ in those with bilateral blindness. A significant utility decrement was found between patients without diabetic retinopathy and those with a sight-threatening health state $(0.748 \mathrm{vs}$. 0.628 , respectively, $p=0.04$ ). Conclusions: The findings suggest that a later diabetic retinopathy health state is associated with a decrement in utility value compared with the absence of retinopathy in patients with T2D. The results may be useful as preliminary input to model-based economic evaluations. Further research is needed to investigate the impact of diabetic retinopathy on health-related quality of life in a sample more representative of the Brazilian population. Arch Endocrinol Metab. 2020;64(5):575-83
\end{abstract}

Keywords

EQ-5D; health-related quality of life; utility values; diabetic retinopathy

\author{
1 Department of Health \\ Sciences, Faculty of Science, \\ Vrije Universiteit Amsterdam, \\ Amsterdam Public Health Research \\ Institute, the Netherlands \\ 2 Faculdade de Medicina, \\ Universidade do Vale do \\ Taquari, Lajeado, RS, Brasil \\ ${ }^{3}$ Faculdade de Ciências Médicas, \\ Universidade Federal do Rio Grande \\ do Sul, Porto Alegre, RS, Brasil \\ ${ }^{4}$ Departamento de Medicina \\ Social, Universidade Federal de \\ Pelotas, Pelotas, RS, Brasil \\ ${ }^{5}$ Serviço de Oftalmologia, \\ Hospital Moinhos de Vento, \\ Porto Alegre, RS, Brasil \\ ${ }^{6}$ TelessaúdeRS, Universidade \\ Federal do Rio Grande do Sul, \\ Porto Alegre, RS, Brasil \\ ${ }^{7}$ Hospital de Clínicas de Porto \\ Alegre, Porto Alegre, RS, Brazil \\ ${ }_{8}^{8}$ Programa de Pós-Graduação \\ em Epidemiologia, Universidade \\ Federal do Rio Grande do \\ Sul, Porto Alegre, Brasil
}

\author{
Correspondence to: \\ Ângela Jornada Ben \\ Department of Health Sciences, \\ Faculty of Science, \\ Vrije Universiteit Amsterdam, \\ Amsterdam Public Health \\ Research Institute, \\ the Netherlands \\ De Boelelaan 1081, $1081 \mathrm{HV}$, \\ Amsterdam, the Netherlands \\ a.jornadaben@vu.nl
}

Received on Jan/21/2019 Accepted on Oct/23/2019

DOI: 10.20945/2359-3997000000223

\section{INTRODUCTION}

$\mathrm{D}$ iabetic retinopathy (DR) is one of the leading causes of preventable visual impairment and blindness worldwide, despite existing accurate diagnostic technologies and effective treatments $(1,2)$.
It is usually asymptomatic until late stages and could lead to a sudden visual loss affecting the individual's functional capabilities (e.g., mobility, independence, self-care, and ability to perform daily activities such as work and leisure) (3). In Brazil, DR accounts for 
approximately $25 \%$ of all years lived with disability from diabetes mellitus (4).

The impact of DR on quality of life (also referred to as health-related quality of life [HRQoL]) has been reported in several countries $(5,6)$. The results suggest that DR severity has a significant negative impact on HRQoL among patients with diabetes. However, this finding is not consistent across studies (5). HRQoL is a complex construct involving an individual's perception of his or her health state (including physical, mental, and social domains) (7). Sociocultural differences may influence HRQoL perception (8). Therefore, it is particularly important to provide information on the DR impact on HRQoL considering the social context (9).

The EuroQol five dimensions (EQ-5D) (10) is the most commonly used generic preference-based measure of HRQoL (other measures include the SF-36 and the HUI-3) (11). It encompasses five health dimensions (mobility, self-care, usual activities, pain/discomfort, and anxiety/depression), all of which contain three severity levels, resulting in 234 possible health states. The health states can be converted into utility values (with a single value representing an individual's preferences for a given health state) based on preferences of the general population (also referred to as tariffs). Utility values range from 1 (equaling full health) to 0 (equaling death). Negative values may also occur indicating that a person's health state is worse than death (12). The obtained utility values can be used to calculate the qualityadjusted life-years (QALY) measure by multiplying the values by the amount of time spent in a specific health state (12). Many national guidelines (such as those from Brazil and the UK) $(13,14)$ recommend using QALYs in economic evaluations to compare benefits from health technologies (12).

To the best of our knowledge, no study has been conducted using Brazilian EQ-5D tariffs to describe utility values according to DR health states. Therefore, this study aimed to establish the utility values for different health states associated with DR in a Brazilian sample to provide input to model-based economic evaluations, and to explore potential differences in HRQoL among DR health states.

\section{SUBJECTS AND METHODS}

\section{Study design and population}

This was a cross-sectional study including a convenience sample of patients with type 2 diabetes mellitus (T2D) who underwent teleophthalmology screening at a public primary care service in Southern Brazil from 2014 to 2016. Patients with T2D who were registered at the service were invited to participate by phone calls or were referred by the service's family physicians for screening. Individuals with T2D who were older than 18 years were included. Patients were excluded if they had type 1 diabetes (TlD; $\mathrm{n}=5,2 \%$ ), cognition problems $(\mathrm{n}=0)$, blindness due to a disease other than T2D $(\mathrm{n}=1,0.4 \%)$, and unreadable retinal photographs due to lens opacity $(n=20,8.6 \%)$. Patients with TID were not included because of the low prevalence of this disease in primary care. Prior to the measurements, study requirements were explained to the patients by one of the three trained family physicians performing the teleophthalmology screening (15). Patients who agreed to participate provided written informed consent. A legal guardian signed the written informed consent in case of blindness. A sample size of 126 patients was required to detect a difference of 0.1 in mean utility value between two DR health states with an $\alpha$ of 0.05 and power of $\beta=80 \%$.

The study was approved by the Ethics Committee of the Hospital de Clinicas de Porto Alegre.

\section{Teleophthalmology screening}

Retinal photographs were taken by the aforementioned trained family physicians. Images of two fields of each eye were captured by using the Canon CR-2 Digital Retinal (Canon U.S.A., Inc., Melville, NY, USA). Retinal photographs were remotely evaluated and classified by two ophthalmologists of the teleophthalmology screening based on the International Clinical Diabetic Retinopathy and Diabetic Macular Edema Disease Severity Scale (16). More details about the teleophthalmology screening training and work process have been described by other authors (15).

\section{Diabetic retinopathy health states}

Five DR health states were defined based on economic evaluation models previously published in the literature (17-19): absent (NoDR), non-sight-threatening (Non-STDR), sight-threatening (STDR), and bilateral blindness (BB). The Non-STDR health state included mild and moderate nonproliferative DR. The STDR health state included severe nonproliferative, proliferative DR, and clinically significant macular edema. The categorization as Non-STDR and STDR 
was based on the worse eye. Patients were asked to report previously diagnosed eye conditions. Patients reporting a complete vision loss in both eyes due to $\mathrm{T} 2 \mathrm{D}$ and presenting retinographic findings suggestive of vision loss due to DR were classified as BB.

\section{Measure of Health-Related Quality of Life - Utility values}

The EQ-5D is a standardized, generic preference-based measure of HRQoL developed by the EuroQol Group (10). The three-level version of the EQ-5D consists of two pages: the EQ-5D descriptive system and the EQ visual analogue scale (EQVAS). The descriptive system comprises five HRQoL dimensions (mobility, selfcare, usual activities, pain/discomfort, and anxiety/ depression). Each dimension has three severity levels (no problems, some problems, and extreme problems). The EQVAS records the patient's self-rated health on a vertical visual analogue scale ranging from 0 to 100, where the endpoints are labeled "best imaginable health state" and "worst imaginable health state" (10). The visual analogue scale can be used as a quantitative measure of health outcome that reflects the patient's own judgment (10). The patients completed the questionnaire before the retinal photographs were taken. The three-level version of the EQ-5D has been validated in Portuguese, and Brazilian tariffs have been published (20).

\section{Description of variables}

Demographic and clinical variables of interest for descriptive analysis were collected from electronic medical records: age (years), sex, self-reported skin color (white or non-white), education level (no/primary education, secondary education, higher education), diabetes duration in years, diabetes treatment, glycated hemoglobin (HbAlc), diagnosis of hypertension, creatinine, albuminuria, dialysis, low-density lipoprotein cholesterol (LDL), triglycerides (TG), high-density lipoprotein cholesterol (HDL), presence of foot ulcers or lower-extremity amputation, previous coronary heart disease, stroke, ophthalmic diseases, and other self-reported comorbidities. We collected the most recent laboratory results available in the patients' electronic medical record within 12 months prior to the screening. Diabetes control was defined as an HbAlc level $\leq 7.0 \%$ (21). Hypertension was defined as current antihypertensive therapy and/or hypertension diagnosis reported in the medical record. Levels of systolic and diastolic blood pressure below $140 \mathrm{mmHg}$ and $90 \mathrm{mmHg}$, respectively, were classified as controlled hypertension. Chronic kidney disease was defined as any abnormal albuminuria in a spot urine sample $(\geq 17$ $\mathrm{mg} / \mathrm{L}$ or $20-200 \mathrm{mg} / \mathrm{g} \mathrm{Cr}$ ) or a glomerular filtration rate $<90 \mathrm{~mL} / \mathrm{min} / 1.73 \mathrm{~m}^{2}(2 \mathrm{l})$. Dyslipidemia was defined as values of LDL cholesterol $\geq 160 \mathrm{mg} / \mathrm{dL}$, or $\mathrm{TG} \geq 150 \mathrm{mg} / \mathrm{dL}$, or $\mathrm{HDL}<40 \mathrm{mg} / \mathrm{dL}$ (men) and $<50 \mathrm{mg} / \mathrm{dL}$ (women) (2l). Dialysis, lower-extremity amputation, foot ulcers, coronary heart disease, stroke, and ophthalmic disease were inquired through direct questions. Ophthalmic diseases included refractive errors, cataract, glaucoma, ocular toxoplasmosis, and other self-reported ocular conditions. Age-related macular degeneration was assessed by two of the aforementioned ophthalmologists through digital retinal photographs and by patient self-report.

\section{Statistics analyses}

Missing data related to demographic and clinical variables (214 [2.6\%] out of 8026 values) were imputed by means of regression models. Descriptive statistics were calculated using pooled data from the 10 imputed data sets. Means \pm standard deviations (SD) were used to describe normally distributed variables, and medians and interquartile range (IQR) were used for nonparametric variables. The normality of variables was evaluated by histogram graphs and the KolmogorovSmirnov test.

The utility values for different health states associated with diabetic retinopathy were assessed with adjustment for potential confounders using analysis of covariance (ANCOVA). The variables included in the adjusted analysis were selected from the two following sources: a) from a theoretical model based on the current literature, those variables associated with HRQoL, such as age, sex, other comorbidities, ophthalmic diseases, and macrovascular and microvascular complications $(22,23)$ and b) from a previous univariate analysis, those variables found to be associated with utility values $(p \leq 0.05)$. Diabetes duration, HbAlc, diabetes control, and type of treatment were not included in the adjusted analysis because they are usually not associated with HRQoL, despite their strong association with DR $(21,24,25)$. Additional adjusted analysis was performed after excluding the cases of BB because this group was very small (two cases).

We opted to perform ANCOVA because there was homogeneity of variances in utility values at each level of 
DR (Levene's test, $p=0.27$ ) and the residuals followed an approximately normal distribution. For the adjusted analysis, we grouped chronic kidney disease, foot ulcers, and lower-extremity amputation into a single variable named "microvascular complications". Coronary heart disease and stroke were grouped into a variable named "macrovascular complications". Cataract, glaucoma, ocular toxoplasmosis, age-related macular degeneration, and other self-reported ocular diseases were grouped into a variable named "ophthalmic diseases". A variable named "other comorbidities" included other self-reported diseases not included in the three previous variables, such as cancer and rheumatologic and dermatologic disorders. Additional interaction analysis was undertaken considering all possible interactions between variables included in the adjusted analysis. IBM SPSS Statistics version 24.0 was used to perform all analyses.

\section{RESULTS}

We included 206 out of the 232 patients who underwent the teleophthalmology screening.
The mean age of the patients included was $63.5 \pm$ 10.6 years, $60.7 \%(\mathrm{n}=125)$ were female, $85 \%(\mathrm{n}=$ 175) were of white ethnicity, and $50.5 \%(\mathrm{n}=104)$ had secondary education. The patients included in the study had a statistically significantly higher mean utility value compared with those who were excluded due to unreadable retinal photographs $(0.765 \pm 0.19$ vs . $0.636 \pm 0.18$, respectively, $p=0.004)$. However, there were no significant differences between included and excluded patients regarding $\mathrm{HbAlc}(7.5 \%$ vs $7.0 \%$, respectively, $p=0.13)$, diabetes control $(68.4 \%$ vs $71.1 \%$, respectively, $p=0.49)$, and diabetes duration (8.7 vs. 8.2 years, respectively, $p=0.71$ ).

The overall prevalence of DR was $23.8 \%(\mathrm{n}=$ $49)$. In all, $15.5 \%(\mathrm{n}=32)$ of the patients had NonSTDR, 7.3\% $(\mathrm{n}=15)$ had STDR, and $1 \%(\mathrm{n}=2)$ had $\mathrm{BB}$ (Table 1). The percentage of patients reporting full health was $25.7 \%(\mathrm{n}=53)$. The mean utility was 0.773 \pm 0.17 in patients with NoDR and $0.739 \pm 0.24$ in those with DR. Patients with DR and no BB presented a mean utility of $0.755 \pm 0.23$, whereas those with $\mathrm{BB}$ presented a mean utility of $0.356 \pm 0.21$. Appendices 1 and 2 provide a more detailed description of the sample

Table 1. Demographic and clinical characteristics of the sample by diabetic retinopathy (DR) health states

\begin{tabular}{|c|c|c|c|c|}
\hline Characteristics & NoDR & Non-STDR & STDR & BB \\
\hline$n(\%)$ & $157(76.2)$ & $32(15.5)$ & $15(7.3)$ & $2(1.0)$ \\
\hline Age, mean (SD) & $63.9(11.0)$ & $60.0(8.8)$ & $66.5(9.1)$ & $63.3(6.1)$ \\
\hline Female, n (\%) & $104(66.2)$ & $12(37.5)$ & $7(46.7)$ & $2(100)$ \\
\hline White, n (\%) & $135(86.0)$ & $23(71.9)$ & $15(100)$ & $2(100)$ \\
\hline \multicolumn{5}{|l|}{ Education level, n (\%) } \\
\hline No/primary education & $44(28.0)$ & $6(18.8)$ & $1(6.7)$ & $1(50)$ \\
\hline Secondary education & $76(48.4)$ & $17(53.1)$ & $10(66.7)$ & $1(50)$ \\
\hline Higher education & $37(23.6)$ & $9(28.1)$ & $4(26.7)$ & 0 \\
\hline $\mathrm{HbA1c}$, mean value in \% (SD) & $7.5(1.9)$ & $8.4(2.1)$ & $8.5(1.5)$ & $8.8(3.1)$ \\
\hline Controlled DM, n (\%) & $88(56.1)$ & $11(34.4)$ & $3(20.0)$ & $1(50.0)$ \\
\hline DM duration in years, median (IQR) & $5(2-10)$ & $6(3-13)$ & $16(5-25)$ & $18(10-26)$ \\
\hline Insulin treatment, n (\%) & $28(17.8)$ & $15(46.9)$ & $12(80.0)$ & $2(100)$ \\
\hline Controlled hypertension, n (\%) & $89(69.0)$ & $15(57.7)$ & $9(69.2)$ & $1(50.0)$ \\
\hline Dyslipidemia, n (\%) & $112(71.3)$ & $23(71.9)$ & $11(73.3)$ & $2(100)$ \\
\hline Macrovascular complications, n (\%) & $36(22.9)$ & $11(34.4)$ & $5(33.3)$ & 0 \\
\hline Microvascular complications, n (\%) & $100(63.7)$ & $21(65.6)$ & $14(93.3)$ & $2(100)$ \\
\hline Ophthalmic diseases, n (\%) & $34(21.7)$ & $3(9.4)$ & $2(13.3)$ & 0 \\
\hline Other comorbidities, n (\%) & $38(24.2)$ & $3(9.4)$ & $6(40.0)$ & $1(50.0)$ \\
\hline EQ-5D utility, mean (SD) & $0.773(0.17)$ & $0.801(0.21)$ & $0.658(0.25)$ & $0.356(0.21)$ \\
\hline EQVAS, median (IQR) & $80(60-90)$ & $75(70-80)$ & $70(50-80)$ & $65(50-80)$ \\
\hline
\end{tabular}

NoDR: absence of diabetic retinopathy; Non-STDR: non-sight-threatening diabetic retinopathy; STDR: sight-threatening diabetic retinopathy; BB: bilateral blindness; DM: diabetes mellitus; SD: standard deviation; IQR: interquartile range; Macrovascular complications: coronary heart disease and stroke; Microvascular complications: chronic kidney disease $(n=136)$, foot ulcer ( $n=2)$, and lower-extremity amputation $(n=1)$. Ophthalmic diseases: cataract, glaucoma, and age-related macular degeneration; EQVAS: visual analogue scale EQ-5D. 
regarding the five EQ-5D dimensions of quality of life according to DR health states.

Table 2 shows the utility values for the different health states related to DR with and without adjustment for potential confounders. The mean utility value of the various DR health states decreased after adjustment. The adjusted mean utility was 0.748 (95\% CI, 0.698 0.798 ) for a NoDR health state, 0.752 (95\% CI, 0.679 - 0.825) for Non-STDR, 0.628 (95\% CI, 0.521 0.736 ) for STDR, and 0.355 (95\% CI, $0.105-0.606)$

Appendix 1. Frequency and proportion of EuroQol five dimensions (EQ-5D) by diabetic retinopathy (DR) health states

\begin{tabular}{|c|c|c|c|c|c|c|}
\hline & & NoDR n (\%) & Non-STDR n (\%) & STDR n (\%) & BB n (\%) & $p$ value $^{*}$ \\
\hline & & $\mathrm{n}=157$ & $n=32$ & $n=15$ & $\mathrm{n}=2$ & \\
\hline \multirow[t]{3}{*}{ Mobility } & No problems & $110(70.1)$ & $21(65.6)$ & $7(46.7)$ & 0 & 0.055 \\
\hline & Some problems & $46(29.3)$ & $11(34.4)$ & $7(46.7)$ & $2(100)$ & \\
\hline & Extreme problems & $1(0.6)$ & 0 & $1(6.7)$ & 0 & \\
\hline \multirow[t]{3}{*}{ Self-care } & No problems & $142(90.4)$ & 28 (87.5) & $10(66.7)$ & 0 & 0.01 \\
\hline & Some problems & $13(8.3)$ & $4(12.5)$ & $4(2.7)$ & 0 & \\
\hline & Extreme problems & $2(1.3)$ & 0 & $1(6.7)$ & $2(100)$ & \\
\hline \multirow[t]{3}{*}{ Usual activities } & No problems & 115 (73.2) & 26 (81.3) & $7(46.7)$ & $1(50.0)$ & 0.01 \\
\hline & Some problems & $39(24.8)$ & $5(15.6)$ & $6(40.0)$ & 0 & \\
\hline & Extreme problems & $3(1.9)$ & $1(3.1)$ & $2(13.3)$ & $1(50.0)$ & \\
\hline \multirow[t]{3}{*}{ Pain/discomfort } & No problems & $61(38.8)$ & $15(46.9)$ & $6(40.0)$ & $1(50.0)$ & 0.97 \\
\hline & Some problems & $91(58.0)$ & $16(50.0)$ & $8(53.3)$ & $1(50.0)$ & \\
\hline & Extreme problems & $5(3.2)$ & $1(3.1)$ & $1(6.7)$ & 0 & \\
\hline \multirow[t]{3}{*}{ Anxiety/depression } & No problems & $80(51.0)$ & $19(59.4)$ & $8(53.3)$ & 0 & 0.26 \\
\hline & Some problems & $67(42.7)$ & $10(31.3)$ & $6(40.0)$ & $1(50.0)$ & \\
\hline & Extreme problems & $10(6.4)$ & $3(9.4)$ & $1(6.7)$ & $1(50.0)$ & \\
\hline
\end{tabular}

NoDR: absence of diabetic retinopathy; Non-STDR: non-sight-threatening diabetic retinopathy; STDR: sight-threatening diabetic retinopathy; BB: bilateral blindness.

${ }^{*}$ Chi-square test.

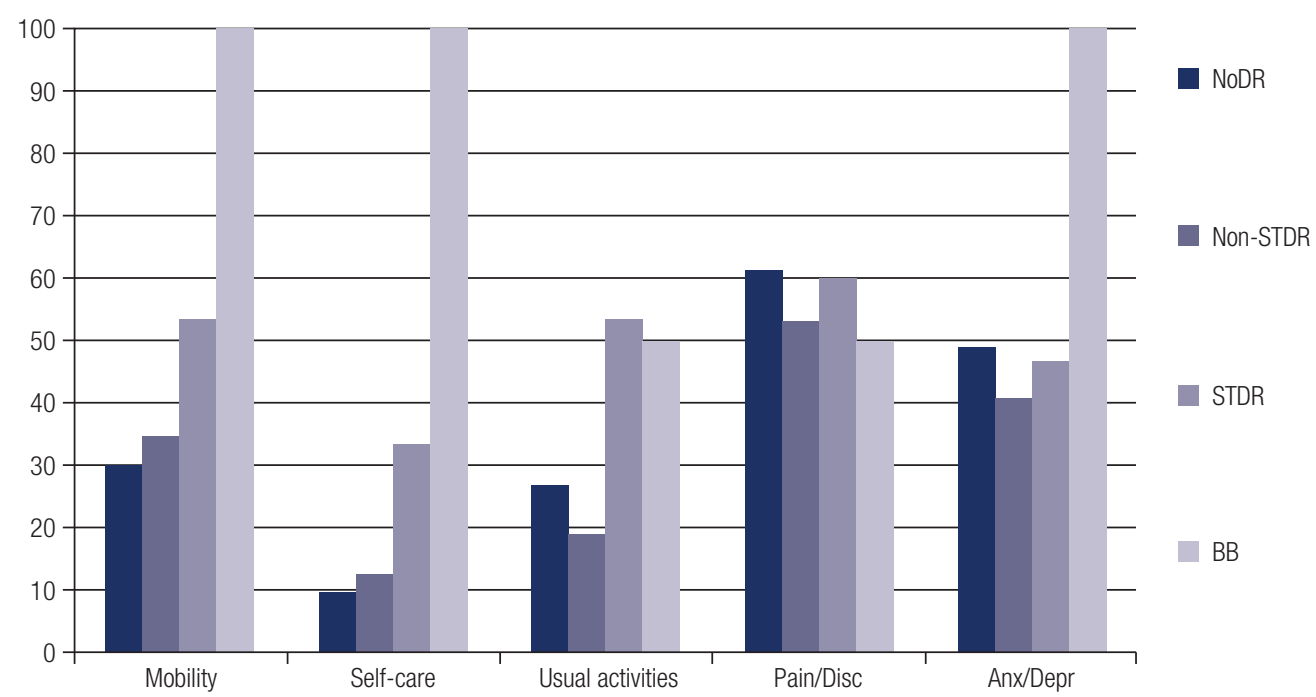

Appendix 2. Percentage of reported problems by dimension of the EuroQol five dimensions (EQ-5D) according to diabetic retinopathy (DR) health states. NoDR: absence of diabetic retinopathy; Non-STDR: non-sight-threatening diabetic retinopathy; STDR: sight-threatening diabetic retinopathy; BB: bilateral blindness; Disc: Discomfort. Anx/Depr: Anxiety/Depression. 
for BB. The adjusted analysis performed after excluding the two cases of BB showed a statistically significant utility decrement between patients at NoDR and STDR health sates $(0.748 v$ vs. 0.628 , respectively, $p=0.04)$. No significant differences were found between NoDR and
non-STDR health states $(0.748 v s$. 0.752 , respectively, $p=1.0)$ and between non-STDR and STDR health states $(0.752 \underline{\text { vs. }} 0.628$, respectively, $p=0.07)$.

The interaction analysis showed statistically significant interactions between DR health states and

Table 2. Mean EuroQol five dimensions (EQ-5D) utility values by variables in unadjusted and adjusted analysis

\begin{tabular}{|c|c|c|c|c|c|}
\hline & $\begin{array}{c}\text { Mean } \\
(95 \% \mathrm{Cl})\end{array}$ & $p$ value & $\begin{array}{l}\text { Adjusted mean* } \\
(95 \% \mathrm{Cl})\end{array}$ & $\mathbf{F}$ & $p$ value \\
\hline \multicolumn{6}{|l|}{ Sex } \\
\hline Female & $0.727(0.695-0.760)$ & 0.001 & $0.572(0.487-0.658)$ & 14475 & 0.001 \\
\hline Male & $0.824(0.783-0.864)$ & & $0.671(0.581-0.759)$ & & \\
\hline \multicolumn{6}{|l|}{ Skin color } \\
\hline White & $0.753(0.724-0.781)$ & 0.020 & $0.601(0.524-0.678)$ & 1290 & 0.258 \\
\hline Non-white & $0.836(0.772-0.900)$ & & $0.641(0.539-0.744)$ & & \\
\hline \multicolumn{6}{|l|}{ DM treatment } \\
\hline Diet & $0.779(0.693-0.866)$ & 0.283 & NA & NA & NA \\
\hline Oral medications & $0.778(0.748-0.808)$ & & & & \\
\hline Insulin & $0.731(0.671-0.791)$ & & & & \\
\hline \multicolumn{6}{|l|}{ Controlled DM } \\
\hline Yes & $0.774(0.743-0.806)$ & 0.359 & NA & NA & NA \\
\hline No & $0.756(0.714-0.798)$ & & & & \\
\hline \multicolumn{6}{|c|}{ Controlled hypertension } \\
\hline Yes & $0.756(0.723-0.789)$ & 0.549 & NA & NA & NA \\
\hline No & $0.774(0.771-0.832)$ & & & & \\
\hline \multicolumn{6}{|l|}{ Dyslipidemia } \\
\hline Yes & $0.751(0.720-0.782)$ & 0.123 & NA & NA & NA \\
\hline No & $0.801(0.752-0.850)$ & & & & \\
\hline \multicolumn{6}{|c|}{ Macrovascular complications } \\
\hline Yes & $0.687(0.629-0.746)$ & 0.001 & $0.563(0.468-0.657)$ & 15786 & 0.001 \\
\hline No & $0.791(0.764-0.819)$ & & $0.679(0.598-0.761)$ & & \\
\hline \multicolumn{6}{|c|}{ Microvascular complications } \\
\hline Yes & $0.745(0.711-0.780)$ & 0.060 & & 0.872 & 0.352 \\
\hline No & $0.804(0.767-0.842)$ & & & & \\
\hline \multicolumn{6}{|l|}{ Other comorbidities } \\
\hline Yes & $0.709(0.653-0.765)$ & 0.020 & $0.608(0.529-0.687)$ & 1757 & 0.187 \\
\hline No & $0.782(0.753-0.811)$ & & $0.634(0.538-0.731)$ & & \\
\hline \multicolumn{6}{|l|}{ Ophthalmic diseases } \\
\hline Yes & $0.714(0.659-0.769)$ & 0.060 & & 2188 & 0.141 \\
\hline No & $0.777(0.748-0.806)$ & & & & \\
\hline \multicolumn{6}{|l|}{ DR health states } \\
\hline NoDR & $0.773(0.746-0.800)$ & 0.001 & $0.748(0.698-0.798)^{\star \star}$ & 5041 & 0.002 \\
\hline Non-STDR & $0.801(0.726-0.875)$ & & $0.752(0.679-0.825)^{\star *}$ & & \\
\hline STDR & $0.658(0.521-0.794)$ & & $0.628(0.521-0.736)$ & & \\
\hline BB & $0.356(0.061-0.651)$ & & $0.355(0.105-0.606)^{\star *}$ & & \\
\hline
\end{tabular}

SD: standard deviation; NA: not applicable, variables not included in the adjusted analysis; DM: diabetes mellitus; DR: diabetic retinopathy; NoDR: absence of diabetic retinopathy; Non-STDR: nonsight-threatening diabetic retinopathy; STDR: sight-threatening diabetic retinopathy; BB: bilateral blindness. *Analysis adjusted by age, sex, skin color, other comorbidities, macrovascular and microvascular complications, and ophthalmic diseases. R square $=0.242 ;$ Adjusted R square $=0.202$. ${ }^{\star \star}$ Bonferroni test: NoDR and BB $(p=0.01) ;$ Non-STDR and BB $(p=0.01)$. 
other comorbidities $\left(\mathrm{F}_{3,66}=3679, p=0.01\right)$; between sex, skin color, and DR health states $\left(\mathrm{F}_{1,66}=6020\right.$, $p=0.01$ ); between other comorbidities, macrovascular complications, and DR health states $\left(\mathrm{F}_{1,66}=8596\right.$, $p<0.001)$; and between skin color and microvascular complications $\left(\mathrm{F}_{1,66}=3974, p=0.05\right)$. The interaction between DR health states and the variables included in the adjusted analysis is presented in Figure 1.

\section{DISCUSSION}

This study established the utility values for different health states associated with DR in a sample of patients with T2D undergoing teleophthalmology screening at a public primary care service in Southern Brazil. The results suggest that a later DR health state is associated with a significant decrement in HRQoL compared to the absence of retinopathy in patients with T2D. Additional interaction analysis suggests that the utility values for different health states associated with DR may depend on a combination of DR with other factors such as sex, skin color, other comorbidities, and macrovascular complications. Additional research is needed to further establish this association.

Research exploring the utility values of different health states associated with DR has provided mixed results (26-29). Heintz and cols. (27) found no difference in mean utility values across various levels of
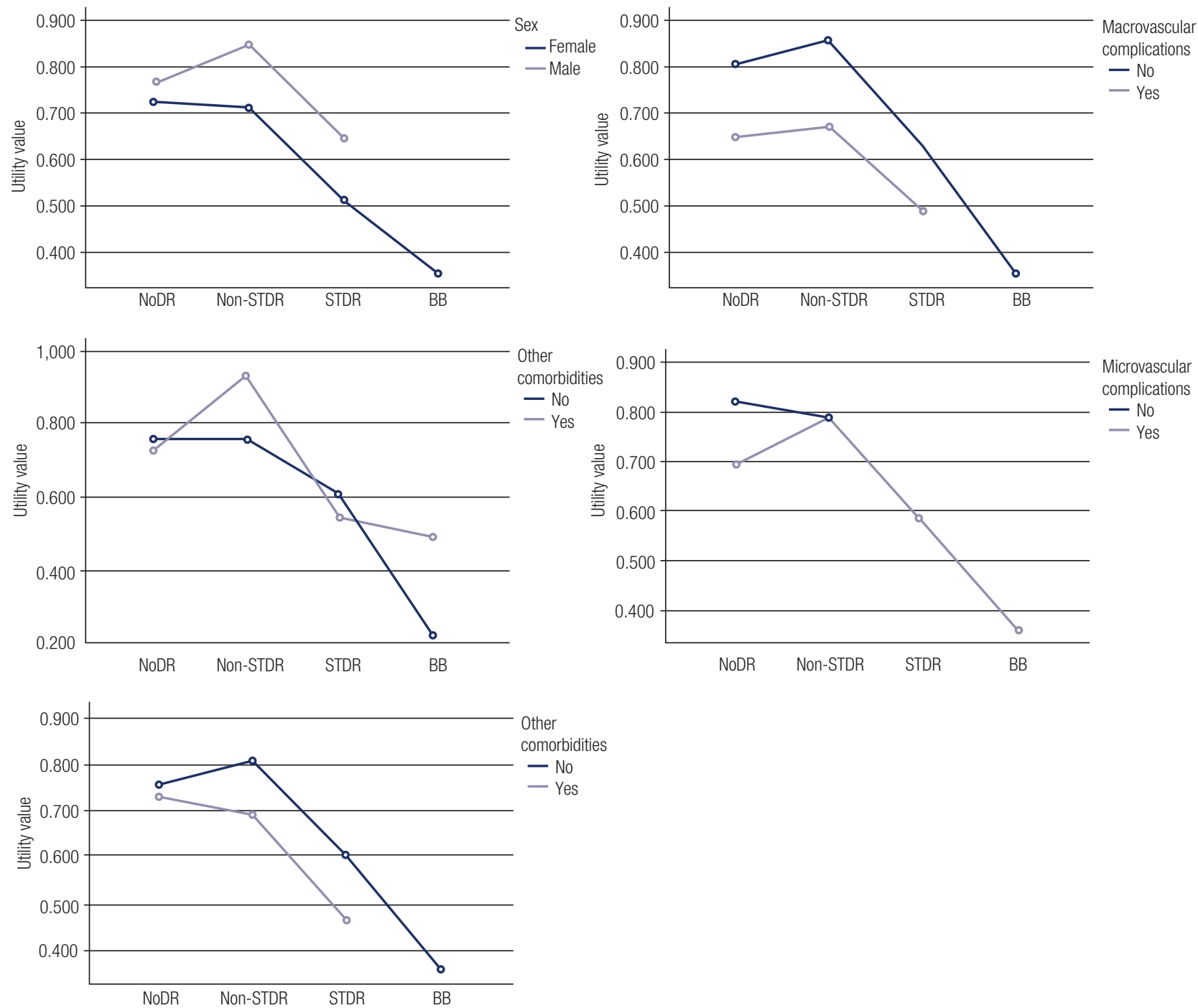

Figure 1. Plots showing mean utility values by diabetic retinopathy (DR) health states stratified by sex, other comorbidities, ophthalmic diseases, and macrovascular and microvascular complications. A statistically significant interaction was observed between other comorbidities and DR health states. NoDR: absence of diabetic retinopathy; Non-STDR: non-sight-threatening diabetic retinopathy; STDR: sight-threatening diabetic retinopathy; BB: bilateral blindness. 
DR severity in a sample of Swedish patients with TID and T2D. Fenwick and cols. also found no differences in a sample of Australian patients with TID and T2D (28). Our study differs from both these studies because it was based on a different population (comprising only individuals with T2D) and included different variables in the adjusted analysis (i.e., did not include variables strongly associated with $\mathrm{DR}$, such as diabetes duration and $\mathrm{HbAlc}$, which are usually not directly related to HRQoL). Similar to our results, Polack and cols. found that late DR health states were associated with a lower mean utility value compared with the absence of DR in a sample of patients with T2D in India (29). Lloyd and cols. found significant utility value decrements associated with lower visual acuity in a sample of TID and T2D patients in the UK (26). The present study also found no HRQoL differences in early DR health states (i.e., between patients without DR and NonSTDR), which is in agreement with other studies suggesting that early DR health states are unlikely to be strongly correlated with any of the dimensions of HRQoL $(27,28,30)$.

This study has a number of limitations that need to be discussed. First, the EQ-5D may not be sensitive enough to detect small differences in HRQoL during early DR health states (27). The validity of EQ-5D compared to other generic preference-based measures of HRQoL (e.g., HUI-3) regarding DR progression is controversial $(26,27)$. Researchers have proposed adding bolt-ons to expand EQ-5D descriptive systems considering visual symptoms however, this is still under investigation (31).

Second, the convenience sample only allowed us to assess patients registered at a primary care service, thus potentially reducing the generalizability of the findings. Therefore, we would advise researchers to only use these numbers as preliminary input to model-based economic evaluations. Nonetheless, it is noteworthy that the mean overall utility value reported in our study $(0.76 \pm 0.19)$ was similar to values found in developed countries, such as the UK $(0.77 \pm 0.27)(32)$ and the Netherlands $(0.74 \pm 0.27)(33)$.

Third, this study did not directly assess visual acuity, which is known to be associated with lower HRQoL in late DR health sates $(34,35)$. Consequently, we had to rely on DR diagnosis/classification by image without adjustment for the visual acuity potential confounder. Nevertheless, to be able to populate model-based economic evaluations, the utility values should be classified according to DR health states instead of visual acuity (27).

Fourth, patients with unreadable photographs were excluded from the study, which may have biased the results due to selective patient exclusion. However, the lower HRQoL presented by the excluded patients compared with those included in the study may be related to the lens opacity instead of DR, since there was no difference regarding diabetes control and duration between them.

Bearing in mind that HRQoL could be different across country populations and that one of the main outcomes of economic evaluations (i.e., QALY gained) relies on utility values, this study was the first attempt to describe HRQoL associated with DR health states in a Brazilian primary care setting based on general population preferences. These results may be useful as preliminary input to model-based economic evaluations. Further research is needed to investigate the impact of DR progression on HRQoL in a representative sample of the Brazilian population.

In conclusion, this study established the utility values for different health states associated with DR in a Southern Brazilian sample of patients with T2D undergoing teleophthalmology screening at a public primary care service. The results suggest that a late DR health state is associated with decrements in HRQoL. The findings may be useful as preliminary input to model-based economic evaluations.

Funding: this study was funded by the Departamento de Ciência e Tecnologia - Ministério da Saúde do Brasil. Rede Brasileira de Avaliação de Tecnologias em Saúde: Pesquisa de Efetividade Comparativa (PEC-REBRATS). Grant number: 57/2013 MCTI/ CNPq/MS - SCTIE - DECIT.

Disclosure: no potential conflict of interest relevant to this article was reported.

\section{REFERENCES}

1. Yau JWY, Rogers SL, Kawasaki R, Lamoureux EL, Kowalski JW, BekT, et al. Global Prevalence and Major Risk Factors of Diabetic Retinopathy. Diabetes Care. 2012;35(3):556-64.

2. Lee R, Wong TY, Sabanayagam C. Epidemiology of diabetic retinopathy, diabetic macular edema and related vision loss. Eye Vis (Lond). 2015;2:17.

3. Willis JR, Doan QV, Gleeson M, Haskova Z, Ramulu P, Morse L, et al. Vision-Related Functional Burden of Diabetic Retinopathy Across Severity Levels in the United States. JAMA Ophthalmol. 2017;135(9):926-32.

4. Oliveira AF de, Valente JG, Leite I da C, Schramm JM de A, Azevedo ASR de, Gadelha AMJ. Global burden of disease 
attributable to diabetes mellitus in Brazil. Cadernos de Saúde Pública. 2009;25(6):1234-44.

5. Yuhara NA, Magistasari D, Ikakusumawati ND, Andayani TM, Kristina SA. The Impact of Severity, Comorbidities, and Complications on Quality of Life: A systematic review in patients with Diabetic Retinopathy. International Research Journal of Pharmacy. 2019;10(4):61-8.

6. Takahara M, Katakami N, Shiraiwa T, Abe K, Ayame H, IshimaruY, et al. Evaluation of health utility values for diabetic complications, treatment regimens, glycemic control and other subjective symptoms in diabetic patients using the EQ-5D-5L. Acta Diabetol. 2019;56(3):309-19.

7. Karimi M, Brazier J. Health, Health-Related Quality of Life, and Quality of Life: What is the Difference? Pharmacoeconomics. 2016;34:645-9.

8. Kagawa-Singer M, Padilla GV, Ashing-Giwa K. Health-Related Quality of Life and Culture. Seminars in Oncology Nursing. 2010;26(1):59-67.

9. Trikkalinou A, Papazafiropoulou AK, Melidonis A. Type 2 diabetes and quality of life. World J Diabetes. 2017;8(4):120-9.

10. EuroQol Group. EuroQol-a new facility for the measurement of health-related quality of life. Health policy. 1990;16(3):199-208.

11. Brazier J, Ara R, Rowen D, Chevrou-Severac H. A Review of Generic Preference-Based Measures for Use in Cost-Effectiveness Models. PharmacoEconomics. 2017;35(1):21-31.

12. Whitehead SJ, Ali S. Health outcomes in economic evaluation: the QALY and utilities. Br Med Bull. 2010 Dec 1;96(1):5-21.

13. REBRATS. Diretriz de Avaliação Econômica. Ministério da Saúde. Secretaria de Ciência, Tecnologia e Insumos Estratégicos. Departamento de Gestão e Incorporação de Tecnologias em Saúde. 2013 [cited 2017 Apr 18]; Available from: http://rebrats. saude.gov.br/diretrizes-metodologicas

14. McCabe C, Claxton K, Culyer AJ. The NICE Cost-Effectiveness Threshold. Pharmacoeconomics. 2008;26(9):733-44.

15. Rosses APO, Ben AJ, Souza CF de, Skortika A, Araújo AL de, Carvalho $G$ de, et al. Diagnostic performance of retinal digital photography for diabetic retinopathy screening in primary care. Fam Pract. 2017;34(5):546-51.

16. Wilkinson $\mathrm{CP}$, Ferris FL, Klein RE, Lee PP, Agardh CD, Davis $M$, et al. Proposed international clinical diabetic retinopathy and diabetic macular edema disease severity scales. Ophthalmology. 2003;110(9):1677-82.

17. Rachapelle S, Legood R, Alavi $Y$, Lindfield R, Sharma T, Kuper $\mathrm{H}$, et al. The Cost-Utility of Telemedicine to Screen for Diabetic Retinopathy in India. Ophthalmology. 2013;120(3):566-73.

18. Kim S-W, Kang G-W. Cost-Utility Analysis of Screening Strategies for Diabetic Retinopathy in Korea. J Korean Med Sci. 2015;30(12):1723-32.

19. Kawasaki R, Akune Y, Hiratsuka Y, Fukuhara S, Yamada M. Costutility Analysis of Screening for Diabetic Retinopathy in Japan: A Probabilistic Markov Modeling Study. Ophthalmic Epidemiol. 2015;22(1):4-12.

20. Viegas Andrade M, Noronha K, Kind $P$, Maia AC, Miranda de Menezes R, De Barros Reis $C$, et al. Societal Preferences for
EQ-5D Health States from a Brazilian Population Survey. Value Health Reg Issues. 2013;2(3):405-12.

21. Standards of Medical Care in Diabetes - 2016: Summary of Revisions. Diabetes Care. 2015;39(Supplement 1):S4.

22. Janssen MF, Lubetkin El, Sekhobo JP, Pickard AS. The use of the EQ-5D preference-based health status measure in adults with Type 2 diabetes mellitus. Diabet Med. 2011;28(4):395-413.

23. Brown MM, Brown GC, Sharma S, Hollands H, Landy J. Quality of life and systemic comorbidities in patients with ophthalmic disease. Br J Ophthalmol. 2002;86(1):8-11.

24. UKPDS Group. Intensive blood-glucose control with sulphonylureas or insulin compared with conventional treatment and risk of complications in patients with type 2 diabetes (UKPDS 33). The Lancet. 1998;352(9131):837-53.

25. Stratton IM, Kohner EM, Aldington SJ, Turner RC, Holman RR, Manley SE, et al. UKPDS 50: Risk factors for incidence and progression of retinopathy in Type II diabetes over 6 years from diagnosis. Diabetologia. 2001;44(2):156-63.

26. Lloyd A, Nafees B, Gavriel S, Rousculp MD, Boye KS, Ahmad A. Health utility values associated with diabetic retinopathy: Original article. Diabetic Medicine. 2008;25(5):618-24.

27. Heintz $E$, Wiréhn A-B, Peebo BB, Rosenqvist $U$, Levin L-Å. QALY Weights for Diabetic Retinopathy - A Comparison of Health State Valuations with HUI-3, EQ-5D, EQ-VAS, and TTO. Value Health. 2012;15(3):475-84.

28. Fenwick EK, Xie J, Ratcliffe J, Pesudovs K, Finger RP, Wong TY, et al. The Impact of Diabetic Retinopathy and Diabetic Macular Edema on Health-Related Quality of Life in Type 1 and Type 2 Diabetes. Invest Ophthalmol Vis Sci. 2012;53(2):677-84.

29. Polack S, Alavi Y, Rachapalle Reddi S, Kulothungan V, Kuper H. Utility Values Associated with Diabetic Retinopathy in Chennai, India. Ophthalmic Epidemiol. 2015;22(1):20-7.

30. Bagust A, Beale S. Modelling EuroQol health-related utility values for diabetic complications from CODE-2 data. Health Econ. 2005; 14(3):217-30.

31. Finch AP, Brazier JE, Mukuria C, Bjorner JB. An Exploratory Study on Using Principal-Component Analysis and Confirmatory Factor Analysis to Identify Bolt-On Dimensions: The EQ-5D Case Study. Value Health. 2017;20(10):1362-75.

32. Clarke P, Gray A, Holman R. Estimating utility values for health states of type 2 diabetic patients using the EQ-5D (UKPDS 62). Medical Decision Making. 2002;22(4):340-49.

33. Redekop WK, Koopmanschap MA, Stolk RP, Rutten GE, Wolffenbuttel BH, Niessen LW. Health-related quality of life and treatment satisfaction in Dutch patients with type 2 diabetes. Diabetes Care. 2002;25(3):458-63.

34. Poku E, Brazier J, Carlton J, Ferreira A. Health state utilities in patients with diabetic retinopathy, diabetic macular oedema and age-related macular degeneration: a systematic review. BMC Ophthalmol. 2013;13:74.

35. Smith DH, Johnson ES, Russell A, Hazlehurst B, Muraki C, Nichols GA, et al. Lower visual acuity predicts worse utility values among patients with type 2 diabetes. Qual Life Res. 2008;17(10):1277-84. 